\title{
Suicide by Cop-A Psychology of Institutional Betrayal
}

\author{
Mark B. Malmin* \\ San Jose State University, San Jose, CA, USA \\ Email: mbmalmin@comcast.net
}

How to cite this paper: Malmin, M. B. (2017). Suicide by Cop-A Psychology of Institutional Betrayal. Psychology, 8, 903928.

https://doi.org/10.4236/psych.2017.86059

Received: March 29, 2017

Accepted: April 27, 2017

Published: April 30, 2017

Copyright $\odot 2017$ by author and Scientific Research Publishing Inc. This work is licensed under the Creative Commons Attribution International License (CC BY 4.0).

http://creativecommons.org/licenses/by/4.0/

\begin{abstract}
This positional paper examines institutional law enforcement (LE) deadly force encounters with the mentally ill in the United States, with an emphasis on those who threaten or attempt suicide by cop while armed with a weapon other than a firearm. Research reveals a disproportionate number of mentally ill people are killed by police during LE confrontations. The social psychology of suicide by cop and the contributory LE institutional facilitation of these encounters is examined. Causational attribution is attributable, in part, to LE epistemological correlation factors that include a one-size-fits all shooting methodology of shooting center mass body-torso that invariably produces death, a lack of LE crisis intervention de-escalation training, and other contributing sociological geopolitical-jurisprudential factors that are elucidated. LE use-of-force is exegetically examined in the legal context of requirements that it be objectively reasonable and necessary. A reduction in homicides of the mentally ill at the hands of LE is conceptually possible if the institutional culture of LE agrees to increase crisis intervention de-escalation training for officers, and LE modifies its shooting tactics, so as to permit discretionary implementation of incapacitating force, permitting a more calculated disabling level of force, using a fewer rounds fired methodology. Such a change in policy and tactics could mitigate the number of mentally ill fatalities with LE encounters, potentially improve community policing relationships, and reduce wrongful death litigations and settlement awards that are routinely paid out by municipalities with tax dollars. The author recommends the implementation of a pilot program that would test the efficacy of these change proposals.
\end{abstract}

\section{Keywords}

Suicide by Cop, Suicide, Assisted Suicide, Police Shootings

\footnotetext{
${ }^{*}$ The author served as a California Peace Officer for 28 years, holding positions of detective, hostage negotiator, FTO, and acting field supervisor. The author's expertise includes extensive Crisis Intervention Training (CIT) field experience with the mentally ill. The author is currently retired and maintains an interest in LE/military warrior culture, stress management, and spirituality. Questions or commentary for the author may be directed to mbmalmin@comcast.net.
} 


\section{Introduction}

The use of deadly force by law enforcement (LE) has a long history in the United States, including many changes and restrictions over the years that have been influenced by public policy, legislation, judicial due process, changing social attitudes, and community policing strategies. All LE encounters with the mentally ill do not end unsuccessfully. The vast majority of LE encounters with the mentally ill go well, and the mentally ill are taken to a psychiatric medical facility to receive treatment. In those cases, however, where the mentally ill are armed with a weapon other than a firearm, and LE uses deadly force, the fatality rates of the mentally ill are high, in part, because officers are trained to shoot multiple rounds at center body torso mass, and this invariable causes death.

Research on the fatalities of the mentally ill at the hands of LE naturally varies in scope and methodology due to the multiplicity of associated and contributing factors of the research, but the data-numbers on this are deleterious. A recent study reported in USA Today estimates that people with mental illness are 16 times more likely to be killed by police. The study reveals that nearly 8 million Americans suffer from serious mental illness, and the police encounters with this population swamp the criminal justice system. Beginning this year, the FBI has agreed to collect and begin reporting the research data on all officer involved shootings (Szabe, 2016)

Anyone who has ever worked the streets knows the calls for police service produce an exponential number of encounters with the mentally ill, and the data on this is never captured because it is almost impossible to document. Many officers would tell you half the people they deal with over and over again in criminality suffer from moral bankruptcy, substance abuse and dependency, but many suffer from varying degrees of personality disorders and mental illness, or some combination of all of the above. In one way or another, mental illness emerges as a variable in a high percentage of police encounters, and many of the calls for service do not originate with a known or reported mental illness issue. The undocumented but high numbers of LE encounters with the mentally ill do not all result in arrest and incarceration, but the National Alliance on Mental Illness (2017) reports that each year 2 million jail bookings in the United States involve mentally ill people (Subramanian, Delaney, Roberts, Fishman, \& McGarry, 2015).

In a study that dealt with LE encounters with the disabled, a Ruderman Family Foundation report published by NBC, revealed almost half of the people who die at the hands of police have some kind of disability (Melber \& Hause, 2016). These replicative corroborating studies create a paradox which Dr. Jennifer Freyd (2008) describes as institutional betrayal, a term used to describe wrongdoings perpetrated by an institution upon individuals dependent on that institution. The betrayal includes failure to prevent or respond supportively to wrongdoings by individuals within the context of the institution. In other words, the very institution, in this case LE, that should be protecting the mentally disabled, is shooting and killing the mentally ill. Where such maleficence is preventable, these homicides become unconscionable representations of institutional ne- 
farious symbiosis. Dr. Freyd's term institutional betrayal was originally used to describe the sexual assault victimization of students at university institutions, but the term is also well suited to describe the victimization of the mentally ill by LE, wherein those who suffer serious mental illness, and are often suicidal, are killed at the hands of their protectors. LE has a unique mandated do-no-harm institutional duty of care, to protect those who cannot care for themselves. There can be no greater analogous institutional betrayal than that of LE shooting and killing the mentally ill in situational circumstances where less lethal force could reasonably be used, but systematically is not, largely due to policies and protocols that inherently promote excessive use of force.

\section{The Rationale for LE Shooting Tactics}

The tactical use of deadly force in most officer involved shooting typologies, where officers are trained to defend themselves against felonious assaults by shooting multiple rounds at center mass, has long been justified by research, science, and the practice has withstood judicial review. Research studies consistently show that shooting suspects once or twice oftentimes does not stop deadly criminal attacks on officers. Comprehensive etiologic research on officer involved shootings reveals that it is tactically necessary for officers to fire multiple rounds at suspects in order for officers to defend themselves against deadly attacks (Jacobo, 2016; Lane, 2016). This self-defense tactic is justified in most officer involved shootings, and it is universally embraced by LE throughout the United States at all state and federal levels.

The general public, however, has little appreciation for center mass shooting, when officers shoot a mentally ill family member 14 times. Grieving family members of those slain by LE may wonder why law enforcement officers (LEOs) had to shoot and kill a suicidal family member who refused to drop a screwdriver when officers yelled commands. Did the police really have to kill him? Mental illness becomes the proverbial elephant in the room no one wants to acknowledge or indecorously illuminate. It affects all races, cultures, and anthropology groups, irrespective of their wealth or geographical zip code. Who does not have a family member or friend that has not been touched by this condition in some variant form of the disorder, and it hardly matters what diagnostic name it goes by if it involves someone we love. LEOs suffer from depression, divorce, anxiety disorders, and from PTSD symptoms resulting from repetitive occupational exposure to critical incidents. The victimology of mental illness represents a cross-section sample of society that spares no one. The disproportionate number of mentally ill killed by LE creates moral consternation for the public. In the movies, the quixotic police hero shoots the gun out of the suspect's hand, always gets the beautiful girl, protects the disenfranchised, and never kills anyone unnecessarily. The fictional LE hero is also never seen writing a police report to explain why he shot a mentally ill person $14 \mathrm{X}$, nor is he ever seen weeping tears of regret as he suffers from PTSD.

In real life, most shootings occur at relatively very close range, from a distance of about 10 feet or so. Suspects are often moving, or running, and the encounter 
with police is sometimes very sudden, such as in the case of a robber exiting the back door of a liquor store as the police officer is approaching the back door at the same time. The adrenaline rush and fear in such a life and death encounter is so dramatic that it distorts one's perception, creating tunnel vision, and it impacts the human body's physiology functions and psyche (Miller, 2006). A host of these known symptoms have been empirically experienced by this author in field conditions that involved high speed vehicle pursuits in excess of 100 miles per hour, foot pursuit chases, and dangerous arrest encounters that were made at gunpoint with armed and dangerous subjects who resisted arrest. One's heart begins to race wildly, breathing suddenly becomes intensely rapid, producing a condition where officers gasp for air as if they just finished a 300-yard sprint. An incredible surge of adrenaline hits the vascular nervous system, and one's normal tone of voice goes up about 10 octaves. Many LEOs, under such stress, find themselves screaming into their radios rather than speaking normally. The adrenaline rush is both terrifying and exhilarating, and perhaps even seductively intoxicating at times.

Such events are highly stressful and dramatic. Behavioral science literature shows these traumatic critical incident exposures can lead to PTSD symptoms in the participants (Baldwin, 2017). There are cases, such as this, where the stress and fear is so dynamic and intense in these encounters, that officers and suspects alike fire multiple rounds at each other from almost point black range, of 10 feet or less, and in these gun battles their collective fired bullets completely miss each other. Even under ideal circumstances, it is not easy to hit a moving target. Add the saliently intense sudden rush of stress, fear, and adrenaline to the equation and it becomes more understandable that simply hitting your target under these conditions reflects success, especially if the suspect is shooting at you, or otherwise trying to kill you. Nevertheless, good training helps prepare and equip officers for such encounters. This is why LE represents the thin blue line.

There is also the phenomenon of drugs and being under the influence that impacts such encounters. Suspects who are under the influence may not feel pain even if they are shot multiple times. This can be especially true for drugs like PCP and others that reduce or eliminate pain altogether. A suspect can be shot multiple times and still keep shooting at the police. Unless a suspect's vital organ is hit, thereby immediately disabling them and eliminating the threat, officers may need to shoot a suspect multiple times, out of pure objective necessity, just to stop a threat. Suspects are also known to wear bullet proof vests or military grade body armor, so that they can survive a gunfight with police officers. For all these reasons, officers are universally trained to shoot center mass, multiple times, so that they don't miss their target, or die in these assaults.

Then there is the issue of terrorism. It has changed everything in LE training. Terrorists are known to wear body vests which carry explosives. They detonate these explosives with a hand-held trigger device. The only tactical way to stop these nihilists from blowing themselves up and killing innocent victims, is to shoot them in the head before they explode their bomb device. For this reason, 
and the fact that torso shots alone may not stop a suspect, LE firearms training also teaches the lethal tactic of effectuating head shots. LE has taught this tactic for many years, but global terrorism has emphasized its need for this training more than ever before. Tactical, repetitive, on-going training allows officers to successfully make these head shots. LE firearms training helps prepare officers for such encounters. Regular training promotes proficiency, utilizing a variety of targets, such as small balloons, narrow bowling pins, 6-inch head silhouettes, pop up targets, and shoot, don't shoot, hostage holding scenarios.

\section{LE Culture and Resistance to Change}

Institutional policing has, at times, embraced a rigid mind-set that resists change. We've always done it this way; why should we change? Sometimes necessity becomes the mother of invention. The perfect example of this is how LE changed its tactics to active shooters. For years, agencies all across the country followed the same general protocols to major shooting incidents. Available officers set up an inner and outer perimeter containment. SWAT would be called but that could take an hour sometimes for the entire team to assemble. On arrival SWAT formulated an assault plan that might be crudely rehearsed once before entry was attempted. If hostage negotiation efforts were not feasible, SWAT would make forced tactical entry with flash bangs to distract the suspect(s) and attempt to terminate the rampage. After mass shooting incidents took many lives in places like Columbine and Sandy Hook elementary school, LE tactics changed, to avoid unmitigated mass casualties of students. Today, agencies send LEOs directly to the scene to engage and stop active shooters. SWAT may still be utilized if the event is protracted, and these folks do an absolutely wonderful job, but field commanders no longer wait in a holding pattern on the outer perimeter, withholding police aid to barricaded dying victims, while lives are continually being lost waiting for SWAT to come and save the day. In the same way that LE re-engineered its tactical approach to active shooters, institutional re-engineering of deadly force is needed to reduce fatalities with the mentally ill.

The institutional pursuit of excellence in LE requires on-going change and adaptation to increased knowledge and understanding, changing conditions, and best practice standards that will save lives. Quality innovative leadership will always debrief critical events, evaluate its own agency's performance, and ask hard, tough questions: How can we do a better job? Do we need to make adjustments in our tactics? All of this is directly linked to community policing and institutional integrity. Malmin (2012) finds that the way society perceives law enforcement's performance, ultimately serves as a barometer for a community's sense of peace and well-being.

Mental illness is a pathology. Officers should never be viewed as executioners where they are called upon to assist the mentally ill. LE's job is primarily a peace keeping function. LEOs should never intentionally be seeking to kill anyone; at least that's the stated goal. This is a community policing issue, a public relations issue, and a liability issue. When it comes to integrity matters of community policing and use-of-force, Malmin (2015) argues that perception is reality in the 
public's mind. The apparent use of excessive force in confrontations with the mentally is something that institutional LE leadership needs to exam if public support for LE is to be pursued and achieved. Is there anything that can be done to mitigate and reduce the number of fatalities with LE confrontations with the mentally ill? The asseverative answer to this is unequivocally yes, however, written policies of LE agencies that deal with use-of-force will need to be amended and modified, and new training will need to be implemented, allowing greater tactical discretion.

While each LE agency in the country has its own carefully worded use-offorce shooting policies, most agencies do not permit warning shots, or the intentional use of tactical disabling wounding shots. With regard to tactical wounding/disabling, it is entirely possible that there is not a single agency in the country that permits this. That policy may have seemed reasonable years ago before there was awareness that the mentally ill were being killed in disproportionate numbers.

LE use of deadly force upon the mentally ill requires rethinking that incorporates a more balanced response to threat level variations. Threat levels are not all equal, nor are they situationally manifested the same, and it would be misleading to argue otherwise, or respond as if they were uniformly singular. Use-of-force tactical response to situational threats need to be measured, reasonable, and necessary, based on objective threat assessment, not imaginary, potential, or hypothetical fear, unsupported by facts or evidence.

Institutional policing needs to modify its shooting tactics with suicidal mentally ill people in a more propitious manner without killing the very people they are supposed to protect and defend. Mitigating these fatalities is an achievable goal. This analysis and criticism is not directed at the courageous men and women who put their lives on the line every day to protect our communities. The analytics here are a reflection of a systemic institutional dysfunction that represents an amalgamation of failed written policy, tactics, and training procedures.

\section{Defining the Mentally Ill in LE Legal Terms}

In California, section 5150 of the Welfare and Institutions Code defines mentally ill people (State of California, 2016), and this law gives LEOs the authority to take such individuals into protective custody for their own safety or the safety of the public. Anyone who, as a result of a mental health disorder, is a danger to others, or to himself or herself, or who is gravely disabled, falls within the provisions of this code. The law allows LEOs to take these mentally ill people to a county psychiatric facility for a 72-hour mental health evaluation and/or treatment. Each state has its own written laws and the code sections will vary accordingly. For purpose of this paper and simplicity sake, the author will use the term " 5150 " to denote mentally ill people who fall within the provisions of the statutory definition. It is noteworthy to mention that section 5150 W\&I Code is not a criminal statue. Once a 5150 subject is stabilized at a psychiatric facility my medical professionals, the person may be released immediately. Unless the person committed some specific crime, there is no criminal charge attached to their 
mental illness. In other words, it's literally not a crime to be mentally ill, absent other factors.

The term suicide by cop identifies 5150s who intentionally confront LE so as to provoke a shooting that results in the 5150's own planned death.

Objective Distinctions in 5150 Suicidal Threats From Other Deadly Assaults on LE

If the shooting tactics previously described (shooting multiple rounds at center mass) are objectively necessary in felonious assaults against officers, and this tactic is justified by research, science, and officer safety, why would officers not use this same strategy on 5150s who threaten officers or who threaten suicide by cop? Suicidal 5150 threats fall into a unique sui generis category all their own. Motivational ideation factors associated with suicide by cop encounters repeatedly demonstrate that the 5150's primary goal is not to kill a LEO, but rather to be killed by a LEO, thus fulfilling a formulated plan to commit suicide, as opposed to murder. Threats should always be taken seriously, but threats alone don't kill officers. Behavioral actions kill officers. Few LEOs have ever actually been killed in 5150 suicide by cop encounters. There may be rare exception(s) to this. Violent criminals who suffer from serious mental illness kill cops annually, but not because of suicidality motivations, mental illness causation, or suicide by cop encounters. Suicidal 5150s who are overtly pleading to be shot by LE are, in fact, being disproportionately killed by LE.

5150s represent a unique class typology for LE. Efficacious intervention with these typology encounters requires special LE crisis intervention training (CIT), but not all officers get this training. Unlike other confrontational felons, 5150s pose a completely different lower threat level, primarily because they are suffering from mental illness, and of those who are suicidal, many seek restorative intervention. Upon reaching rock bottom, some 5150s will want to eliminate their emotional pain through suicide. To effectuate that end goal, they may hope for intervention, but nevertheless attempt suicide by cop. Neither of these two options (getting help or effectuating suicide) motivates suicidal 5150s to kill officers, a contraindicated response which antithetically defeats anhedonic suicide, and prevents officers from doing their dirty work for them.

This juxtapositional pathological proclivity does not eliminate irrational threat mutations nor does it guarantee predictability. From an officer safety point of view and the 21 -foot knife rule, mentally ill people are situationally unpredictable and potentially dangerous to LEOs. Most 5150s, however, are usually a greater threat to themselves, by virtue of their own mental pathology. This does not mean 5150s don't know right from wrong, or that their behavior is less illegal, or less culpable, if they disobey police commands.

Armed 5150s always pose a potential threat to officers. This cannot be under emphasized simply because 5150s need help. Suicidal people have zero self-esteem and oftentimes an inadequate healthy functioning social support system. Treatment abstention and pain avoidance evolves into death ideations, planning, and methodology execution. Frenetic confrontational 5150s may seek one last exis- 
tential human validation, encouragement, or reason to live, before they completely give up on life. Such suicidal typologies create a unique humanitarian threat distinction from all other criminals who feloniously attack officers.

When the Mentally Ill Seek Suicide by Cop and They Plead, Shoot me!

It is important to remember that this goal or demand is up for discussion, and there is intrinsic uncertainty in both the request and in the desired outcome. If this were not true, virtually all of these 5150s would just commit suicide on their own, and they wouldn't wait for the police to arrive and attempt to talk to them, or offer them help. The threat level to officers in these encounters differs from other felonious assailants who would attack, injury, or kill officers. This represents a saliently important variable to threat assessment. This goes to motivation and intent and it should play an interactive role that should influence and impact LE intervention response.

In cases where the mentally ill person is suicidal and suicide by cop becomes the manifest plan to achieve the stated goal, the mentally ill invariably challenge officers: just shoot me! This starts out as a plea request. There is a negotiation process of pleading that takes place in these encounters. The author knows this to be true as a practitioner with empirical experience working the streets, dealing with mentally ill subjects, and from having talked several out of suicide, some of which were armed with a knife, or as in the case of a juvenile, ready and threatening to jump off the roof of a building.

While each case and confrontation is situationally unique, there seems to be an initial period of time where contact is made between LE and the mentally ill that involves some element of negotiation. In the alternative, the contact collapses; but even in the worst cases, there is a window of time, albeit small, wherein the subject and the officer engage in some level of conversation or negotiation. The officer and the suspect both have a limited symbiotic measure of influence over the encounter. If the officer lacks de-escalation training and/or experience, he or she may rely exclusively on their LE authority and verbal commands. If the officer approaches the suspect too quickly and gets too close, this escalates the stakes and the threat level. If the suspect refuses to comply with orders to drop the knife, this may impact the encounter and make negotiations more difficult, or impossible, especially if the officer has gotten too close to the suspect to begin with. If we study these cases we will see that in almost every one, including the ones that are not handled as well as they could be, the mentally ill subject typically speaks to the officer(s) briefly, if only to yell threats, or plead, shoot me!

\section{A Paradigm of Institutional Shooting Tactics: A Case Study Review of Kajieme Powell}

The case of Kajieme Powell on August 19, 2014, serves as an example of how fast these encounters can turn deadly. Kajieme Powell was shot and killed in St. Louis, MO. This occurred 10 days after Officer Wilson shot and killed Michael Brown, in Ferguson, MO. The Michael Brown shooting of Ferguson exploded into rioting, based largely upon misinformation and minority public perception 
and outrage which claimed white LE racial bias and unlawful deadly force was used against Michael Brown, an unarmed black man. Rioting began almost immediately in Ferguson before facts were known and it spread to other cities across the country. Police officers were shot and murdered in New York, Texas, and elsewhere around the country. A thorough post-shooting investigation by the FBI and the Department of Justice civil rights investigative unit which interviewed and re-interviewed witnesses, and collected forensic evidence, ultimately determined the shooting to be lawful.

The Powell shooting could happen in any city in America, resulting in another Ferguson. The analytics of the Powell shooting and the potential Ferguson like rioting repercussions that could metastasize from such a similar event, from a public safety point of view, should be reason enough for Chiefs of Police and city administrators to study the Powell shooting with a mind-set of looking at policy, tactics, and training, that could prevent a repeat of the same or similar event.

The St. Louis City Attorney's Office (CAO) post-investigation report (2015) of the Powell shooting provided a detailed synoptic overview of the shooting and timeline of the events that led to the shooting. The event began in the 8700 block of Riverview Blvd. in St. Louis, at approximately 12:15 PM on August 19, 2014, when Powell entered a convenience store, took a food item and two sodas from the store, and refused to pay for the merchandise. When the store clerk informed Powell he was going to call the police if the items were not paid for, Powell stated he didn't care (p. 7). Powell did not want to negotiate with the clerk. He wanted the clerk to call the police. It can be deduced from his behavior that Powell's intent was not theft, but suicide by cop. Powell exited the store but never absconded or fled from the scene; he threw the food item into the street, and carefully placed the soda on the sidewalk, and began pacing back in forth while cell phone video shows him mumbling incoherently, at times, to himself and to passing by pedestrians as he waited for the police to arrive (p. 12). The first 911 call to police was made at 12:18 PM. Other 911 calls followed. The store clerk retrieved the food item from the street and tried to calm Powell down but that failed. When the store clerk approached Powell a second time outside the store he tried to reason with Powell and asked him if he could retrieve the sodas, Powell yelled obscenities at the clerk and threatened to kill him, or anyone else that got near the sodas (p. 5).

Powell waited for the officers, pacing back and forth on the sidewalk for approximately 10 minutes. A two-man unit arrived at 12:28 PM. The marked police vehicle was driven over the curb and partially onto the sidewalk in a controlled diagonal parking maneuver that directly faced Powell standing on the sidewalk. Powell quietly stood still for a moment, facing the officers, and very intentionally gave them time and space to exit their vehicle. Standing approximately 20 -feet away, Powell displayed a large knife in his hand at which time he began screaming at the officers "shoot me now", taking several quick steps toward them (pp. 11-12). Powell then stopped abruptly and backed away several feet. This showed cognition and behavioral hesitation. Neither officer fired his 
weapon in those preliminary seconds.

Powell's "shoot me now" statements should have triggered a mental health suicide by cop red flag. One of the officers had CIT training in 2012, but this did not appear to be an influential factor in the encounter. Verbal de-escalation appeared to be preempted by both LEOs simultaneously yelling verbal commands. The negotiation process began the moment both officers exited their vehicle, and it became saliently visible when Powell stopped abruptly and backed away from the officers in the first 3 - 5 seconds. The negotiation process was being tested during those brief seconds. Powell wanted to see how the officers would react. He tested them.

Powell disobeyed multiple police commands to drop the knife. After Powell once again took a step toward the officers he was immediately shot this time by Ofcr\#1 standing adjacent to the right/front passenger door of the patrol car, from an estimated separation distance of 15 feet. The first officer's shot was fired 15 seconds from the time the officers exited their patrol car at approximately 12:28 PM. After the first shot was fired, both officers continued to fire rapidly at the suspect, striking him 10 times as Powell staggered forward, falling to the ground from a raised 18-inch platform retainer wall above the sidewalk. Powell's forward falling momentum caused him to roll forward on the sidewalk and this brought him to rest on the sidewalk 2 - 3 feet away from Ofcr\#1. Video shows Ofcr\#1 then fired 2 more rounds into Powell at point blank range. Ofcr\#2's rounds were fired from a standing position by the left/front headlight and hood area of the patrol car.

The St. Louis CAO post-investigation report (2015) reviewed the shooting facts of this incident and issued a 40-page report summarizing the shooting, along with witness statements and other evidentiary facts. Tactics were not endorsed or challenged. Only the legality of the shooting was assessed (King, 2015). Autopsy results showed Powell had 13 entry gunshot wounds resulting from rounds fired by the officers, and 5 exit wounds. Twelve $9 \mathrm{~mm}$ casings were recovered as evidence at the shooting scene, consistent with duty issued ammunition the officers carried. The autopsy report revealed one of the entrance wounds on Powell's upper left arm was likely a re-entry wound, meaning a bullet entered, exited and then re-entered Powell's body. That explains Powell being shot 12 times, but having 13 entry wounds. In the CAO report (Section 5: Autopsy Report) the Medical Examiner reported that the sequence of the shots could not be determined, but that none of the shots would have been immediately fatal. Each officer shot the suspect 6 times. Four of the 12 shots would have subsequently been fatal. The Medical Examiner opined it was possible for the deceased to have still been moving after collapsing on the ground (p. 13).

\section{Discussion}

\section{Use of Force Analysis of the Powell Shooting}

The witness who video-taped the shooting on his cell phone, and events leading up to the shooting, described Powell's behavior as being "crazy". This wit- 
ness made spontaneous observational comments (as a direct eye witness) that are memorialized on the audio-video recording. The audio recording captures Powell yelling profanities and the words "shoot me now" during the confrontation. The video speaks for itself in terms of its evidentiary value which depicts Powell's behavior, demeanor, and mental state of mind. Normal functioning, mentally stable people don't take soda and refuse to pay for it, threaten to kill the store clerk for asking permission to retrieve the unpaid-for merchandise, then pace back and forth outside the front of the store muttering or babbling to themselves, while waiting over 10 minutes for the police to arrive. [Powell entered the convenience store 13 minutes before the shooting unfolded]. All of these variables collectively would seem to suggest, at least to a discerning person, or well-trained police officers, including dispatchers who are trained to ask important, pertinent questions, that mental illness might have been a variable in this unfolding event.

This seemingly self-evident fact is mentioned parenthetically only as an incongruity because the police 911 dispatchers in this case adamantly denied that mental illness was ever brought to their attention by any of the witnesses who reported this event on 911 emergency lines (p. 5: 25). While that may have been odd, and entirely true, it also does not eliminate the need for LE to ask specific mental health questions and gather vital information that is relevant during 911 call-takings. Asking more detailed questions about Powell's demeanor while documenting his irrationality and connecting the dots would have ostensibly provided more information to dispatchers, and presumably to responding officers. Examples of Powell's irrationality are documented in the CAO Report wherein Powell was described as being emotionally agitated and seemingly angry for no apparent reason, yelling profanities, but to no particular person, pacing back and forth, muttering to himself, incoherently at times, and by statements Powell made to the store clerk, threatening to kill him, or anyone else that got near the soda drinks he set on the sidewalk (p. 5: 7, 12).

The issue of Powell's mental health was raised by public criticism and community sentiment that followed the shooting. In response to unfavorable press and social media criticism, and perhaps in anticipation of pending civil litigation which was sure to follow, an affirmative police denial of having any knowledge that Powell suffered from mental health issues was asserted in the post-shooting investigation report issued by the City (p. 25). The city's self-defense posture was not legally inappropriate. The city clearly had, and continues to have, an absolute legal right to assert its position and defend itself against excessive use-offorce allegations, wrongful death civil litigation, failure to follow best practice standards, and contributory duty of care negligence.

Notwithstanding legal due process issues, the right to self-defense, and the presumption of innocence, from a purely constructive training point of view that critiques and debriefs performance, tactics, and areas where improvements are needed, questions pertaining to a seemingly obvious mental health issue should always be asked about, if LE is interested in acquiring all the critical facts availa- 
ble when taking such 911 calls. Mental health information intrinsically becomes valuable to responding officers, and it helps them establish a mind-set for tactics. This would seem to be axiomatically true in nearly all tumultuous police encounters, but especially so with encounters that involve weapons or the potential for violence. The absence of mental health information might lead officers to think in more tactical terms rather than in therapeutic intervention strategies, if they are only being told a suspect is aggressive and threatening. Knowing that same person was emotionally hysterical and irrational, without provocation, would represent critical information and context for responding officers. The acquisition, assessment, and dissemination of accurate facts impact LE's tactical approach to the scene, including the method, manner, and way LEOs approach and contact people. A subject's prior or current history and their present state of mind can become extremely useful in weighing methodology technique and use-of-force considerations that might be required, including the availability of specialized resources.

The officers' tactical arrival on scene, from this author's CIT-hostage negotiation practitioner perspective, gives a subtle clue of mind-set, which appears to be one of confrontation rather than de-escalation. The officers didn't need to drive over the curb and onto the sidewalk in a show of force, or get that close, unless confrontation was desired sooner rather than later. Even so, if the officers had backed away from the suspect a few feet to increase the distance between the suspect and themselves, that dilatory tactic might have helped, and allowed for at least a few more seconds to attempt de-escalation verbal tactics. None of this may have worked. In any event, under the pejorative circumstances that existed, and which the officers were confronted with, they still had 15 seconds to take aim before the first shot was fired.

It can be circumstantially argued, based on the video evidence of this shooting, Powell wanted to negotiate in this encounter. Using cognition, suicidal people often hesitate in their pursuit and commitment to kill themselves. As a typology, many who are suicidal are known to change their mind and subsequently want to live. This is well documented in research literature. Practitioners, including LE, see this all the time. There is often a continuum of progression which leads from ruminating about suicidal ideations, to developing plans that produce attempts, or completions, according to research studies reported by the U.S. Department of Veterans Affairs (2017) and the American Psychiatric Association (2004). Research by Dr. Lisa Firestone (2011) finds people change their minds because they are conflicted. Firestone explains that ambivalence is always a factor when it comes to suicide, because part of the 5150 wants to live and the other part is self-destructive. Many conflicted 5150s probably hope LE will talk them out of their suicidal plans.

If there was never intrinsic reluctance, hesitancy, or vacillation to end their life, all of these 5150s would commit suicide and not wait for LE to come and offer them help. Powell was no different. He waited for the officers to arrive, then he waited for them to exit their vehicle and take a defensive stand. Had 
Powell adamantly made up his mind to commit suicide, he could have done so in many different ways without the police, but if he wanted to commit suicide by cop, and do so without any negotiation period, then he would have arguably advanced upon the closest officer, the driver, exiting his patrol car, and we can be assured the officer would have been forced to shoot him immediately. This shooting event took only 15 seconds but if no negotiation period had been desired, it would have ended in the first 3 seconds, by charging the officer exiting the driver's seat of the patrol car. There is a desired period of negotiation to most of these encounters which suspects allow.

LE is not sufficiently trained in most cases to deal with this. LEOs do only what their limited training encourages them to do. Etiology research shows LEOs disproportionately kill mentally ill people. In a manifestly diminished capacity of unintentional occupational toxicity and institutional betrayal that is absent malfeasant intent, suicidal 5150s, and officers alike, are institutionally victimized at times by the moral conundrum of such encounters.

The Powell video reveals the last two shots of the 12 that were fired into the suspect came at point blank range by Ofcr\#1 as the suspect lay prone on the sidewalk, already incapacitated, having been shot 10 times before the final 2 shots. The last 2 shots ostensibly may have been fired because Powell was still moving slightly, and the officer may have perceived that as an on-going threat, but the optics of this from the video make it appear excessive. The medical examiner found 13 entry wounds in Powell. A single shot to the upper quadrant of the chest, to disable and incapacitate the suspect, conceivably could have changed the outcome, providing the officers had such tactical training, or that their firearms policy and General Orders permitted such a tactical disabling shot. From a purely visual perspective of public optics, the shooting and number of rounds fired appears excessive (notwithstanding its legality). This scenario, or some version of it, plays out all across America 52 weeks of every year.

\section{Tactical Training Issues \& Argument}

From a dispassionate point of view, critical thinking, and tactical analysis, the Powell shooting video demonstrates the absence of a less than lethal tactical shooting protocol attempt, a lack of situational patience, verbal de-escalation skills, and overall training. The absence of discernment in how to synergistically apply patience with tactics was a likely contributing factor. Officers are not sufficiently taught the necessity or benefits of patience. Patience isn't typically something they emphasize in the academy or the Field Training Officer (FTO) program. In the police academy, LEOs are taught the fundamental basics: laws of arrest, report writing, verbal commands, how to be decisive and take action. They start out by relying on their statutory authority to give commands, and if people don't comply, institutional culture teaches them to enforce the law, make an arrest, and if the violator resists, overcome resistance, "kick ass" when necessary, and take people to jail.

After the academy, recruits enter an intense field training program where a ubiquitous institutional subculture oftentimes favors and unintentionally pro- 
motes use-of-force over conflict resolution thinking, along with a contumelious view that talking to people suggestively makes one a social worker, a pejorative term most warrior cops and FTOs disassociate from self-image views they hold. LEOs who embrace a stereotypical Hollywood subculture image of danger and action don't want to be viewed as social workers or librarians. Good FTOs do not simplistically think this way, but institutional mores and subculture help shape and mold recruits. FTOs have historically been known to tell recruits fresh out of the academy: Forget everything they taught you in the academy, kid; $P \mathrm{~m}$ going to teach you how to become a cop (Malmin, 2013: p. 748). If recruits want a career in LE they have to please their FTOs and pass the FTO training program to keep their job. Right or wrong, subculture also promotes a tightly knit epistemological view that cops must take care of their own. On occasion, when it comes to use-of-force, subculture may infer looking the other way (p. 744).

Administrators don't talk about institutional deviance, let alone acknowledge this because they are not hired to change LE subculture, but subculture represents a reality on the street, which Chiefs tolerate or acquiesce to by default if they fail to set clear expectations, standards of excellence, and behavioral conduct that is both required and precluded within the organization. Deadly force with 5150s may at times fall into a very fine subjectively grey line of obfuscated idiosyncratic LE subculture. FTOs are not teaching recruits to "just be patient" if someone resists and shoot fewer rounds when possible. Culture teaches LEOs to take care of business and decisively eliminate the threat. When officers get the metaphorical circumstantial green light to shoot, that's exactly what they do, and it's all interlinked with policy, tactics, and training. Subculture becomes a contributing factor. In the case of 5150s, there isn't enough LE CIT de-escalation training or patience. Patience isn't an issued commodity; it's developed through training, life experience, discernment, and sage.

In the Powell shooting, the officers unnecessarily drove up onto and over the curb and partially onto the sidewalk in what appears to be an authoritarian show of force that immediately placed the officers unnecessarily too close to the suspect. While this was completely unnecessary from a tactical point of view, and actually disadvantageous, it was manifestly intentional. The officers could have tactically backed away to provide a cushion of space so that verbal negotiations had a more realistic chance, but they did not. Screaming at a mentally ill subject, a tactic that rarely works with our spouses, or anyone else for that matter, also doesn't work well with a mentally ill person who is also screaming or perhaps trying to vent rage. This simply is not a helpful de-escalation tactic with the mentally ill, even though the commands to drop the knife were appropriate. When commands are ignored, other verbal de-escalation tactics should be attempted or employed. None of these tactical observations reflect wrong doing or malice on the part of the officers, as much as they reflect LE training, or the lack of it. Powell's death was a tragic incident that reflects a systemic LE training failure in America when it comes to encounters with the mentally ill.

The institutional LE firearms policy of shooting multiple rounds at center 
mass is a major contributing factor to the fatalities of the mentally ill, because it reflects the perceived institutional gold standard in LE, and it offers no optional lessor use-of-force modality with fewer rounds fired. For all practical survivability purposes, this virtually eliminates tactical discretion by dictating a singular response to all threat assessments. Center mass target acquisition shooting completely eliminates the concept of discretionary tactical precision shooting and it inherently promotes overwhelming force when lessor force could be equally effective in mitigating, controlling, or eliminating situational threats posed by 5150 s.

The systemic fatality failure of 5150s resulting from LE encounters is perpetuated by an endogenous institutional sociology that fails to fully recognize, value, or implement comprehensive CIT training, a flawed one-size-fits all shooting methodology, and by a culture that is resistant to change or outside criticism from those who do not belong to the LE family. If you are not part of the LE family, outside observers and critics have no standing to suggest how tactical LE strategies should be implemented, least of all firearms shooting tactics where officer safety culture can become exaggeratedly sacrosanct. This same epistemology and mind-set that circumvents common sense in this regard indirectly contributed to the 1991 beating of Rodney King and the subsequent riots that followed that event, and the multiple civil rights excessive use-of-force law suits that followed in subsequent years. The ubiquitous institutional pain compliance use-of-force strategy failed with Rodney King.

The conceptual policy of pain compliance, efficacious on its face in most cases, was inherently flawed and it failed because LE never recognized exceptions to the general rule [some people simply will not comply with LE commands], nor were alternative tactics and training offered in those cases where pain compliance simply failed to work. The result was that Rodney King was unnecessarily beaten to a pulp because officers followed their training. If city administrators had hypothetically been able to somehow preview the Rodney King beating and we, the people, could have asked them if this was how they wanted their officers to conduct business, all of them would have presumably said no. Yet, the same thing is occurring with the shooting fatalities of the mentally ill where compliance once again fails to work, and alternative use-of-force tactical shooting methodologies are not being offered. The result: excessive use of deadly force is pervasively being used because this is what LEOs are tactically trained to do. It would be difficult to envision government officials like mayors, chiefs of police, or city managers, who would view the optics of the Kajieme Powell shooting today, and not find the facts of this case equally disheartening, and not voice a soliloquy that we can do better if municipalities provide more comprehensive, improved, tactical training.

\section{Reasonable and Necessary Force}

State laws permit reasonable and necessary LE force to overcome resistance. Where the threat is reduced, overwhelming force can be reduced, especially when officers have 15 seconds, even under the worst of conditions. In many 
other situations, officers have minutes. These encounters require shooting policy changes and tactical training. All the training in the world, good will, and sagacious crisis intervention de-escalation tactics won't preclude lethal force shootings in all cases, but where lethal force is necessary against the mentally ill, it also should not generate routine overwhelming deadly force wherein a 5150 is shot $14 \mathrm{X}$ center mass by LE. Such shootings may be tenuously legal but perceptually many appear morally unnecessary, excessive, borderline criminal, and they diminish public support for LE.

Public support greatly impacts our social institutions and it either builds or diminishes trust in our democratic institutions such as LE. The emergence of public outrage from Ferguson over the perceived unlawful use of deadly force by LE was initially fueled by false witness statements, disinformation, suspicion, anger, and a public perception of wrong doing that was unsupported by factual evidence. In the immediate absence of unfolding factual evidence, a false narrative of LE bias and excessive use-of-force spread through the media and social media and helped create social protests that quickly turned into rioting that spread to New York City, Oakland, Los Angeles, and Houston. Several LEOs were subsequently murdered across the country in the ensuring months that followed. While public rage may have been misguided in factual ways before pending exculpatory evidence emerged in Ferguson, the same cannot be said for many other documented LE shootings that have occurred where excessive use-of-force allegations have been proven.

Public outrage in all of these events is thematically linked to public perceptions of LE's institutional malfeasant use of deadly force, all of which are not necessarily inclusive or exclusive of 5150 fatality encounters. Public outrage has consequences in a democratic society that go far beyond voting. Public support is what sustains government; the absence of public support will ultimately destroy democratic governance. The institution of LE cannot survive or function optimally without public support at all levels. Public trust in LE is one of the principle factors that make America different from other third world countries. If we lose that foundational trust, we will lose the safeguards and catenation that holds our social fabric and other institutions together. The political science and sociology of ignoring public opinion and anger produces deep distrust of institutional government leadership. When this reaches a critical boiling point of distrust and anger, riotous events like Ferguson erupt. Ferguson arose out of a deep distrust the governed had for its institutional leadership. The Kajieme Powell shooting, which occurred only a few miles away, only served to further erode community trust in LE 5150 use-of-force confrontations.

Fear Requirements for Using Deadly Force Must Be Objectively Reasonable

There are statutory jurisprudent restrictions that govern LE use of deadly force, including individual agency guideline restrictions. Only reasonable force is permitted in California to effect an arrest, prevent escape, or overcome resistance under penal code section 835a PC (State of California, 1998). Other bind- 
ing judicial opinions use the phrase reasonably necessary. Specificity becomes critical because deadly force is not permitted for minor offenses, including resisting arrest misdemeanors and non-compliance to LE verbal commands. Officers usually defend their use of deadly force by saying they feared for their life. The courts have held that such fear needs to be objectively reasonable based on the situational circumstances. In other words, requisite fear cannot be grossly overstated, patently manufactured, or imaginary, without supporting facts or credible circumstantial evidence. This prevailing legal standard has been upheld by various US Supreme Court decisions (Rutledge, 2008). This issue may raise its ugly head occasionally where a LEO shoots a fleeing unarmed suspect in the back. Extremely rare public safety exceptions may permit such deadly force where there is documented history of credible articulable facts to support an assertion that further crimes or death to others would likely occur if escape were permitted with such a dangerous suspect. As a general rule, the requisite fear of self-defense against death or great bodily injury is very difficult to prove in justifying deadly force in cases where a LEO shoots a fleeing suspect in the back. Jurisprudent common sense by the trier of fact usually prevails in such cases.

In the matter of 5150s, the critical legal question becomes a matter of whether the amount of force used by LE to kill suicidal mentally ill people is objectively reasonable under the $4^{\text {th }}$ Amendment. If legal evidentiary facts could be shown to a trier of fact that less lethal force, with fewer rounds fired, could have been reasonably used with precision disabling targeted efficacy, then the prototypical killing by center mass target acquisition shooting with multiple rounds fired would presumably be excessive and unreasonable. This would seemingly violate the $4^{\text {th }}$ Amendment, potentially the $14^{\text {th }}$ Amendment equal rights clause, and possibly the $8^{\text {th }}$ Amendment as it pertains to unusual, cruel or excessive lethal force that irrevocably violates the fundamental right to life, liberty, and the pursuit of happiness.

LE deadly force, used to overcome resistance, statutorily cannot be unreasonable overwhelming force, a systemic by-product of a predominantly singular institutional methodology for overcoming resistance, if such an intervention tactic is deemed on its merits to be objectively excessive and unreasonable by $4^{\text {th }}$ Amendment metrics. In a $4^{\text {th }}$ Amendment civil rights case, a one-size-fits-all tactical methodology of firing multiple rounds at center mass might be deemed overwhelming and excessive, rather than objectively reasonable, when other less lethal tactics could have been effectively implemented.

Law Enforcement Threat Assessment Factors Should Impact Intervention

Present day training teaches LE officers to take head shots. Why? To kill? Yes and No. Can overwhelming deadly force ever be used? Yes and No. By logic, definition, and statutory law, overwhelming force would presumably be excessive, and unlawful if deemed unreasonable, or unnecessary; however, such a seeming contradiction of terms might be reasonably justified and permitted in syncretic moral and legal terms in those cases where it is the only way to absolutely objectively ensure a real and present threat is immediately stopped or eliminated. In 
such cases, death will likely result with LE head shots. The stated purpose of head shots, however, is not to kill per sé, but to ensure with certainty the threat is eliminated or otherwise stopped. Death with such tactics is highly likely.

LEOs should never optically appear to be administering capital punishment, executing street justice, or be using excessive force. The courts administer justice, but unfortunately, so do the police, and District Attorneys are reticent to file criminal charges against officers who put their lives on the line for society, for cases that juries are less likely to convict upon. LEOs are condignly extended great prosecutorial discretion, judicial latitude and benefit of doubt. Unfortunately, duplicity exists here because LE trains for deadly [terrorist] head-shotkills, but not for life-saving tactical upper quadrant chest shots that would save the lives of 5150s.

LE deadly force with suicidal 5150s represents a disingenuous double standard, without regard to the unnecessary death it produces. This defies core values of policing. LE has the tactical capability to successfully make head-shotkills. LE has the tactical capability of making upper quadrant non-lethal disabling chest shots or upper thigh shots, but intentionally chooses not to offer such live-saving training on this, or even allow precision tactical disabling shots as a matter of policy, even where it could be safely effectuated. This impacts public perception and community policing bonds. At the very core of policing lies the ability and necessity of LE officers to make critical life and death use-of-force decisions using appropriate discretion under stressful conditions. Attenuated threat assessment and discretion need to be jointly factored into cognitive use-of-force decisions by those who do the shooting, not by administrators sitting behind a desk.

A pencil can be a deadly weapon. In-custody inmates from the jail who are attending criminal trials, and sitting in the courtroom with their attorney at the defense table, have been known to stab their attorney in the ear with a pencil, apparently trying to kill them. In the hands of a killer, a pencil could be a deadly weapon used to perniciously stab someone in their eye, their carotid artery, or even the brain by perforating the nasal/sinus cavity. If a suicidal mentally ill person threatens to kill a LEO with a pencil, should LE shoot the suspect multiple times at center mass? If a pencil, screwdriver, or a broken beer bottle can be a deadly weapon, should they all become the moral equivalent of a firearm, or a 7-inch blade hunting knife?

Threat levels vary. At what point does requisite jurisprudential legal fear requirements for deadly force stop becoming objectively reasonable by any common-sense evidentiary standard? In measuring threat potentiality, common sense would seem to suggest that neither a pencil nor a knife is quite the same as a firearm. Use-of-deadly force to overcome resistance involves a two-prong test: it necessitates a demonstrative ability for LEOs, under stressful field conditions, to reasonably perceive and measure threat assessments objectively on a factual basis, but even more importantly, it requires LEOs to exercise perspicacious pedantry to calculate and implement reasonable retaliatory amounts of force to 
overcome confrontational threats. While threat assessment preliminarily becomes an individual officer's perceptual issue, and certainly one that should not be completely misread or overly exaggerated, it becomes the LEO's reaction response to situational threats that is objectively assayed with the greatest legal scrutinization through the local county District Attorney's Office, the US Department of Justice civil rights division and investigative resources of the FBI, and through litigation evidence presented to the trier of fact.

The post-shooting legal litigation of self-defense and officer safety in these reviews will invariably have less to do with disputes over perceptual threat assessment realities, as it will with the amount of force that was used to overcome situational threats and non-compliance. The core issue will predictably assay excessive force.

\section{A One-Size-Fits-All Methodology Promotes Excessive Force}

LE's one-size-fits shooting methodology of firing multiple rounds at center mass completely disregards important distinctions in threat level assessment, and it removes critical judgment and discretion out of the equation where less lethal force with fewer rounds fired could be reasonably employed, utilizing precision tactical shooting. This strategic epistemology culture reduces moral excellence to base levels by fallaciously promoting an implied, suggestively conclusive view that overwhelming deadly force is necessary to ensure officer safety.

The LE practice of center mass body shooting intentionally attempts to target vital organs like the heart. This tactic should not be applied to 5150 encounters where a lower threat level exists, and the mentally ill person is not armed with a firearm. In the case of suicidal 5150 encounters, center mass target acquisition shooting with multiple rounds inherently promotes overwhelming force. This defeats the concept of applying discretionary judgment to threat assessments. To further complicate this, a psychological stress phenomenon known as "sympathetic-contagious" shooting is also known to impact officers who face the same threat. Cover officers may feel compelled to shoot because their partner is shooting at a threat source, or because the sound of gunfire connotes a threat, even if it is not directed at a specific officer.

This may explain, in part, why officers frequently shoot a $515014 \mathrm{X}$ or more at center mass (Baram, 2006; Joyner, 2010). We need to train officers to avoid or guard against the phenomenon of sympathetic-contagious shooting, and emphasize that it is permissible to not shoot. The officer who fails to shoot, or chooses not to shoot, needs to confidently know with co-worker reassurance he/she is not throwing their partner under the bus. This is a training issue. It is entirely possible and reasonable for 2 LEOs to face and perceive the same threat, but have separate differing mind-sets, where one does not shoot, because his/her partner was taking action, and that action reduced their need to duplicate the shooting officer's efforts. Is your agency teaching this important concept to officers so they can factor it into their decision-making process? Could situational perception for obligatory cover-shooting be for the wrong reasons, not based on objective necessity at times? Is your agency providing training on this to offi- 
cers? The issue of contagious shooting and awareness against this needs to be carefully examined.

Former FBI SWAT commander and tactical firearms instructor Chuck Joyner states that he has witnessed contagious shooting on the range during training exercises, and he writes, "When an officer uses deadly force, it must be because of an individual determination that the shooting was lawful as dictated by Tennessee vs. Garner, 471 U.S. 1 (1985), and was within department policy. 'I shot because my buddy shot' doesn't hack it and won't bode well in court" (Joyner, 2010: p. 1). There are serious liability issues that can surface with excessive use of force upon the mentally ill.

The FBI conducts all sorts of research on LE issues and provides invaluable training and assistance to agencies all around the world. Their training on crisis intervention and hostage negotiation training is world class. This author called the FBI's Headquarters about the issue of contagious-sympathetic shooting, and inquired if the Bureau was conducting any research on this issue. An agent informed this author in a phone conversation that the Bureau has not done research into this, nor is it providing any awareness training to its Quantico Academy recruits or visiting LEOs. Since the FBI maintains an auspicious Behavioral Science Unit (FBI.gov), hopefully it will consider the phenomenological issue of contagious shooting and liability in future curriculum. Further replicating studies into this phenomenon would help LE better assess the impact this may have on LE shootings.

\section{Sagacious Training Changes Everything}

For better or for worse, performance is directly linked to the quality and frequency of training. LE learned a valuable lesson on this from the Newhall Incident in California in 1970. In the Newhall incident 4 CHP officers were out-gunned and murdered by 2 felons. Officer tactics and safety procedures came into review and a number of tactical training measures were implemented as a result of this shooting, to prevent future officer fatalities.

A post shooting investigation alleged, perhaps apocryphally, that one of the slain CHP officers in this incident emptied his expended brass cartridges from his revolver to reload during the firefight, and then placed the empty brass casings in his jacket pocket. This was said to have been discovered by the coroner who reportedly was said to have found the brass casings in the officer's uniform jacket pocket. During a gunfight, an officer should never be worrying about his empty brass casing shells, nor should he/she be wasting precious time putting the spent casings in his jacket pocket in the middle of a gun battle. Why would anyone do this? The answer would seem to be that people resort to what they know or always do when under stress. Stress and training play an interactive role in cognitive thinking and how people perform under stress. Under life threatening conditions, people can go into autopilot (Nuwer, 2016). They arguably revert to what they know.

The Newhall incident was immediately reported all across the country as an officer safety training issue. Remedial officer safety training tactics were subse- 
quently implemented, teaching officers not to pick up their spent brass shell casing during firearms training, so as to prevent officers from doing this under stress in a real life and death gunfight battle. After many years elapsed, a select few members of LE now recently claim brass casings were never found in the officer's jacket pocket, and that portion of the Newhall incident is opined to be false. The original account of the Newhall incident was considered to be credible by most tactical range instructors in LE because the practice of LEOs picking empty their brass up off the ground was a fairly common practice, when officers went to range training. On their official agency website dedicated to the Newhall Incident, the CHP does not specifically acknowledge or deny the historical post investigation reports of the brass casings that were allegedly found in one of the CHP officer's jacket pocket, nor does the CHP aver a positional statement to clarify the truth of the matter regarding the expended shell casings, except to say tactical training changes were implemented to enhance officer safety (State of California, 2017).

What is clearly undisputed is the fact that subsequent to this horrible incident at Newhall, the CHP immediately began teaching officers to not pick up their brass casings during range shooting exercises until training was completed (Schraer, 2012). This would seem to lend some credence to the possibility that the Newhall incident was told correctly to begin with. If the practice of LEOs picking up brass at the range was known to never have occurred anywhere, or have any basis in reality, then it would be non sequitur for LE to teach officers not to do this. The recent disputatious denial of this incident by a small number of people after all these years, would seem to be disingenuous, since the practice of picking up brass was a common practice decades ago. This Newhall denial (of shell casings being picked up) is likely to be a matter of agency in-house deference and brotherhood respect to the officers who lost their lives at Newhall, wherein the denial by some is meant to protect the dignity of those officers and avoid tarnishing their memory by any tactical officer safety error or culpability that may have contributed to their own deaths. In any event, the perceptual and reported analytics of the Newhall incident taught LE to not pick up their brass during a gunfight.

The tragic relevance and lessons learned from Newhall are linked to training that teaches officers how to avoid tactical errors. Good training helps prevent catastrophic failure from tactical errors. Good training is efficacious. During tactical range training, LEOs are trained to drop their brass on the floor, reload, cover each other and not worry about their brass or their empty magazines on the floor. Today, LEOs no longer pick up their brass or put it in their pockets, as some did years ago. When range training is completely finished, only then do officers sweep the floor or pick their brass up off the ground. Officers do exactly what they are trained to do, but this requires proper training to begin with. The relevance of Newhall is not based on whether brass casings were actually picked up or not; that doesn't matter. The importance of Newhall is based upon the conceptual understanding that officers do what they have been trained to do, 
and for this reason, prophylactic training is now provided to officers, teaching them not to pick up their spent casing shells in a gunfight. Good training saves lives. Better training could also save 5150 lives.

Behavioral science research reveals that high quality repetitive training is immensely beneficial to officers; and that LEOs who receive such training, who are exposed to stressful conditions, perform measurably better than officers who do not receive the same cutting-edge training (Nuwer, 2016). Good training sets standards of excellence, inculcates good habits that promote consistency, improves performance and proficiency, and helps reduce catastrophic failure. Under stress, people usually do what they have always practiced and done, either by habit or by disciplined training. There is also such a thing as poor training or inadequate training, and this can potentially be as ineffectual or pernicious as no training, in some cases. This is why best practice sets an objective proven standard for the industry. To put learned behavior into its proper ideologic perspective, the problem has never been that officers can't learn to successfully perform with proper training; the problem has always been there is either a complete absence of critical training, or an insufficient amount of it. Collectively, as an occupational typology, LEOs generally do exactly what they are trained to do [notwithstanding anomalies of aberrational behavior, accidental failure, negligence, fatigue failure, or disobedience], and this is consistent with the anthropological science of learned behavior.

The historical argument administrators proffer against warning shots and tactical disabling-wounding shots has been the stated fear that this would create too many shootings. While this concern sounds reasonable, the argument is deceptively specious. Officers are demonstratively quite capable and adept at learning and implementing new training which they receive. In fact, LEOs generally do what they are critically trained to do. This is why high quality repetitive training is so important. Training establishes performance standards, and it promotes proficiency, moreover, it reduces litigation.

Officers will not be shooting every 5150 they talk to and this holds especially true if agencies are promoting, teaching, and emphasizing best practice CIT verbal de-escalation skills, as they should. Any spike in LE shootings would be off-set by a drop in homicides from fewer 5150s being killed at the hands of LE. This would represent an excellent investment in community policing that would be reasonable to argue and defend, and also legally justify. Your mentally ill son is alive because we only shot him once with tactical precision.

\section{Leadership Analysis of Liability Issues}

The sociology of this issue may be the primary barrier for some police administrators who loathe to initiate change within an institutional culture that embraces a mind-set that this is how we've always done it, and outsiders have no standing on how to instruct LE on deadly force tactics. Could LE successfully implement tactical modifications that mitigate 5150 fatalities? Absolutely! Trained officers who have 3 - 5 seconds to aim at a noncompliant threat source, not armed with a firearm, are quite capable of strategically shooting targeted 
body zones. Leadership fails if it doesn't ask hard questions about this or it never implements or attempts new strategies. If doing the right thing was easy, everyone would do it. Resistance to this proposal will intrinsically have little to do with tactical feasibility analytics or LE capability performance, but everything to do with institutional culture.

Some will argue that training cost money. This holds some merit otherwise all officers would receive CIT training, but not all training automatically costs more money. Firearms training will always be required but allowing officers more discretion won't unduly inflate or break any agency's existing training budget. While funding is an issue, the morality of taking human life also cannot be undervalued simply because good training costs money. Good policy promotes best practice, saves money, and reduces litigation. Administrators who failed to promote CIT training and reasonable, measured deadly force tactics, put their agencies and cities in a vulnerable position of legal liability. Settlement awards cost more than good training.

Liability should be a matter of concern for municipalities and counties who face deep pocket law suits for failing to train officers properly on the tactics of less lethal force that could have been reasonably used. If best practice isn't being followed, or cities fail to train their officers in best practices standards that save lives, this opens a door to wrongful death law suits, where the burden of proof is merely a prima facie preponderance of the evidence (Landers, 2017). City managers, mayors, and chiefs of police should consider these issues. If it can be shown in court that a LE agency could have reasonably used effective, less lethal force, with fewer rounds fired at body areas other than center mass, but the agency simply didn't teach, offer, or even permit this, or follow best practice standards, is there any doubt who will prevail in court?

\section{Proposal: A Tactical Shooting Policy That Mitigates 5150 Fatalities}

Where the LE use of deadly force in self-defense is reasonably necessary, or simply unavoidable in 5150 encounters, selective, tactical, intentional force that is disabling should be discretionarily available to officers, wherein fewer rounds may be fired, and the option of target acquisition other than center mass is permitted and promoted by regular on-going training. This requires changes in written use-of-force policies and in tactical shooting training. Officers have the right to defend themselves, but they should also have more discretion in self-defense shooting tactics. Currently, officers who fail to shoot multiple rounds at center mass are actually violating their tactical field training! This proposal would not prohibit nor recommend change to the current practice of shooting center mass when necessary, but the proposal would affirmatively permit discretionary tactical disabling force in situational 5150 threat encounters that do not involve a firearm. This would remove the written policy preclusion of incapacitation through intentional tactical precision shooting that wounds, rather than kills, and eliminate the one-size-fits all methodology of firing multiple rounds at center mass under all conditions. This would reduce 5150 fatalities. No one can tell an officer when to shoot. This becomes an individual per- 
ceptual issue of threat assessment. No one can limit the number of rounds an officer shoots, because this is situational also. Multiple rounds may not be necessary in all cases. Self-defense shooting tactics should be an individual choice officers are reasonably allowed to make on their own.

\section{Recommendations}

This author proposes a 3-year pilot program that tests the efficacy of a more calculated intentional use of force policy that permits discretionary implementation of incapacitating force, using a single disabling tactical shot (or fewer rounds fired) methodology rather than the customary multiple shots fired at center mass. This would apply to 5150 threat situations where a suspect is armed with a weapon other than a firearm. If such a pilot program proves successful with public support in large metropolitan test populations, the policy could be gradually implemented on a national level by local democratic governance. The efficacious impact of this would mitigate the number of mentally ill fatalities in law LE encounters all across the nation. This policy could also potentially ameliorate LE community policing relations, and reduce multimillion dollar wrongful death settlements that municipalities seem willing to matter-of-factly pay out as unavoidable collateral damage.

\section{References}

American Psychiatric Association. (2004). Practice Guidelines for the Assessment and Treatment of Patients with Suicidal Behaviors. In Practice Guidelines for the Treatment of Psychiatric Disorders Compendium (2nd edition, pp. 835-1027).

Baldwin, D. (2017). Critical Incident Stress Information Sheet. Los Angeles County Department of Mental Health; David Baldwin's Trauma Information Pages, Copyright (c)1995-2017. http://www.trauma-pages.com/h/cisinfo.php

Baram, M. (2006). How Common Is Contagious Shooting? ABC News, 27 November 2006, 1-9. http://abcnews.go.com/US/LegalCenter/story?id=2681947\&page=1

Firestone, L. (2011). Suicide: What Therapists Need to Know (pp. 1-6). American Psychological Association. Education Directorate, Continuing Education in Psychology. https://www.apa.org/education/ce/suicide.pdf

Freyd, J. (2008). The Psychology of Betrayal Trauma: Memory, Health, and Gender. March 2008. http://dynamic.uoregon.edu/jjf/institutionalbetrayal/\#introduce

Jacobo, J. (2016). Experts on Why Police Aren't Trained to Shoot to Wound. ABC News, 7 July 2016, 1-10.

http://abcnews.go.com/US/police-trained-shoot-wound-experts/story?id=40402933

Joyner, C. (2010). Fighting the Contagious Fire Phenomenon. PoliceOne.com, 29 January 2010, 1-5.

https://www.policeone.com/police-products/firearms/articles/1996906-Fighting-the-co ntagious-fire-phenomenon/

King, C. (2015). No Criminal Charges For Police Who Shot and Killed Kajieme Powell. The Huffington Post (US Edition), 3 November 2015, 1-7.

http://www.huffingtonpost.com/entry/kajieme-powellcharges_us_5638e217e4b00a4d2e Obf256

Landers, D. (2017). Proving Wrongful Death in a Civil Case. Nolo.com. (n.d.), Uploaded 
26 January 2017.

http://www.nolo.com/legal-encyclopedia/proving-wrongful-death-civil-case.html

Lane, E. (2016). Why Do Police Shoot So Many Times? FBI, Expert Answer on Officer-Involved Shootings. NOLA.com, The Times Picayune, 9 March 2016, 1-5. http://www.nola.com/crime/index.ssf/2016/03/police_shootings_nopd_jpso_eri.html

Malmin, M. (2012). Changing Police Subculture. FBI Law Enforcement Bulletin, April 2012, 1-5. https://leb.fbi.gov/2012/april/changing-police-subculture

Malmin, M. (2013). Warrior Culture, Spirituality, and Prayer. Journal of Religion and Health, 52, 740-758. http://link.springer.com/article/10.1007/s10943-013-9690-5 https://doi.org/10.1007/s10943-013-9690-5

Malmin, M. (2015). Police Misconduct, Racism, and Excessive Use of Force-Failure Analysis, Commentary, and Recommendations. Open Journal of Social Sciences, 3, 119. https://doi.org/10.4236/jss.2015.38001

Melber, A., \& Hause, M. (2016). Half of People Killed by Police Have a Disability: Report. NBCNews.com, 14 March 2016, 1-7.

http://www.nbcnews.com/news/us-news/half-people-killed-police-suffer-mental-disabi lity-report-n538371

Miller, L. (2006). Officer-Involved Shooting: Reaction Patterns, Response Protocols, and Psychological Intervention Strategies. International Journal of Emergency Mental Health, 8, 239-254. https://www.psychceu.com/miller/Miller_OIS.pdf

National Alliance on Mental Illness (2017). Law Enforcement and Mental Health (pp. 1-3). https://www.nami.org/Get-Involved/Law-Enforcement-and-Mental-Health

Nuwer, R. (2016). Stress Training for Cops' Brains Could Reduce Suspect Shootings. Scientific American, 20 September 2016.

https://www.scientificamerican.com/article/stress-training-for-cops-brains-could-redu ce-suspect-shootings/

Rutledge, D. (2008). Reflex Fire. PoliceMag.com, 1 May 2008, 1-5. http://www.policemag.com/channel/careers-training/articles/2008/05/reflex-fire.aspx

Schraer, M. (2012). Setting the Record Straight on the Newhall Incident. PoliceOne.com, 9 May 2012, 1-5.

https://www.policeone.com/officer-shootings/articles/5504658-Setting-the-record-strai ght-on-the-Newhall-Incident/

State of California (1998). California Penal Code Section 835a /leginfo.legislation.ca.gov. http://leginfo.legislature.ca.gov/faces/codes_displaySection.xhtml?lawCode=PEN\&secti onNum $=836.5$

State of California (2016). California Welfare and Institutions Code, section 5150. leginfo.legislation.ca.gov.

http://leginfo.legislature.ca.gov/faces/codes_displaySection.xhtml?lawCode=WIC\&secti onNum $=5150$

State of California (2017). The Newhall Incident. chp.ca.gov. https://www.chp.ca.gov/home/about-us/the-history-of-the-california-highway-patrol/ milestones-in-time/the-newhall-incident

Subramanian, R., Delaney, R., Roberts, S., Fishman, N., \& McGarry, P. (2015). Incarceration's Front Door: The Misuse of Jails in America. Vera Institute of Justice, 4.

http://archive.vera.org/sites/default/files/resources/downloads/incarcerations-front-do or-report.pdf

Szabeo, L. (2016). People with Mental Illness 16 Times More Likely to Be Killed by Police. USAToday.com, 1-2.

http://www.usatoday.com/story/news/2015/12/10/people-mental-illness-16-times-mor 
e-likely-killed-police/77059710/

The St. Louis City Attorney's Office (CAO) (2015). St. Louis Circuit Attorney's Office Report Regarding the Review into the Shooting Death of Kajieme Powell. City of Louis, MO: City Attorney's Office, 3 November 2015.

http://www.circuitattorney.org/docs/Report\%20to\%20the\%20Community\%20Powell.p df

U.S. Department of Veterans Affairs (2017). Suicide Risk Assessment Guide. [DOC] (n.d.)/Retrieved January 28, 2017 from

http://webcache.googleusercontent.com/search?q=cache:EA1Rdlhf4MIJ:www.mentalhe alth.va.gov/docs/suicide_risk_assessment_guide.doc $+\& \mathrm{~cd}=1 \& \mathrm{hl}=\mathrm{en} \& \mathrm{ct}=\mathrm{clnk} \& \mathrm{gl}=\mathrm{us}$

Submit or recommend next manuscript to SCIRP and we will provide best service for you:

Accepting pre-submission inquiries through Email, Facebook, LinkedIn, Twitter, etc. A wide selection of journals (inclusive of 9 subjects, more than 200 journals) Providing 24-hour high-quality service User-friendly online submission system Fair and swift peer-review system Efficient typesetting and proofreading procedure Display of the result of downloads and visits, as well as the number of cited articles Maximum dissemination of your research work

Submit your manuscript at: http://papersubmission.scirp.org/

Or contact psych@scirp.org 